\title{
Researching for Change in a Globalising Asymmetric World
}

\author{
Edwin Blake \\ University of Cape Town, \\ South Africa \\ edwin@cs.uct.ac.za
}

\author{
Ineke Büskens \\ Research for the Future \\ Grabouw, Western Cape, South \\ Africa \\ ineke@researchforthefuture.com
}

\author{
Andy Dearden \\ Sheffield Hallam University, \\ Sheffield, UK \\ a.m.dearden@shu.ac.uk
}

\begin{abstract}
The field of research on Information and Communication Technology (ICT) in the service of social development (ICTD) is ripe for reframing. The asymmetries of the world are currently mirrored in the aims, practice and outcomes of too much ICTD research. The consequence is that people who might benefit from creative use of current and emerging technologies all over the world are excluded from the social processes and benefits of innovation and knowledge production. The ICTD research community's widespread dissatisfaction with this situation haunts ICTD gatherings.

In this workshop we want to explore critical alternatives to the current practice. We intend drafting and articulating critical alternatives for future research that is emancipatory, inclusive and oriented towards globally sustainable futures.

To achieve this we first want to acknowledge and expose the vastly different knowledge interests and agendas of the various stakeholders. By examining a series of questions we shall then strive for a responsive reformulation of our approaches in a way that will not easily settle into a new orthodoxy. This will mean that we need to examine not only research and action agendas, transformation, inclusiveness, and power relations, but also our own personal growth and care for ourselves as actors in transformation.

It is fortuitous that the $5^{\text {th }}$ decennial Aarhus conference comes on the target date for the achievement of the United Nations Millennium Development Goals. What next? We want to ensure that after 2015, the research approaches that are adopted and promoted in ICTD are actually structured in the service of development. An ICT that is for Development cannot be realised by blindly replicating global asymmetries where aims and approaches are defined by the powerful and imposed on those at the margins.
\end{abstract}

\section{Author Keywords}

ICT for Development, Emancipation, Power.

\section{ACM Classification Keywords}

Copyright $(2015$ is held by the author(s). Publication rights licensed to Aarhus University and ACM

5th Decennial Aarhus Conference on Critical Alternatives August 17-21, 2015, Aarhus Denmark
K.4.m. Computers and Society: Miscellaneous

\section{OVERVIEW}

This workshop aims to develop a framework of critical alternatives for research that seeks to apply Information and Communication Technology (ICT) in the service of social development (ICTD) in a globalising asymmetric world.

ICTD research aims to improve lives for billions of people, but vast divides (culturally, geographically and financially) make mutual understanding and shared purpose difficult to accomplish in practice. Research actors, including research participants, researchers, funders and other stakeholders have vastly different knowledge interests and are often unaware of how different their agendas are. As a consequence, people who might benefit from creative use of current and emerging technologies (both in the North and the South) are often absent or excluded from the social processes of innovation and knowledge production.

Questions of how research in ICTD can be organised and practiced, and how innovation can be stimulated towards more promising futures, need to address the interplay between power, knowledge interests, technology creation and quality of life.

Questions include:

- How can research agendas and questions be framed in ways that include the voices that are currently marginalised;

- How can research be designed, structured and practiced to create the kind of knowledge that instigates and supports emancipatory social change;

- How do responsive and transformatory research processes allow for participation in, and gain recognition in, the various discourses of answerability, accountability and research quality;

- How can the intentionalities and aspirations of all the research actors (including researchers, research participants, funders, and other stakeholders) be made transparent, shared and negotiated with justice;

- How can radically different knowledge perspectives be integrated in the research ecosystem;

- How can researchers and practitioners position themselves in relation to manifestly unequal power relations (ethnicity, gender, religion, age, sexuality etc.) in contexts where we are working; 
- How do we become aware of the issues in ourselves and our environments that need to be seen and addressed in order to design for or work towards better quality of life on a personal and a global scale;

- How can practices of self-care and self-knowledge support researchers in dealing with the challenges and stresses the research process will present them with;

- How can researchers' processes of personal change contribute to research quality and impact.

This workshop will bring together researchers and practitioners working at the nexus of ICT and development for social change with the aim of drafting and articulating critical alternatives for future research that is sufficiently emancipatory, inclusive and oriented towards globally sustainable futures as to be described as ICT for Development.

\section{SIGNIFICANCE}

The Aarhus decennial conferences stand for human centred systems development. The global spread of digital ICT requires us to recognise that human centeredness extends to the whole of humanity.

The early years of the 21 st Century have seen great interest in the potential of Information and Communication Technologies in addressing social and economic challenges in areas such as healthcare, education, poverty reduction, governance, social inclusion etc., both in the global South and in so called 'developed', or 'WIERD' countries (Western, Industrial, Educated, Rich and Democratic). The United Nations set 2015 as their target date for the Millenium Development Goals (MDGs) and state that "After 2015 efforts to achieve a world of prosperity, equity, freedom, dignity and peace will continue unabated." Innovative application and usage of Information \& Communication Technologies (ICTs) are playing an important role in addressing many of these challenges. ICT and Development (ICTD) or ICT 'for Development' (ICT4D) is a growing field of research in many places. However, the Aarhus conference series has not yet examined this domain in detail.

Critical discourses in ICTD have highlighted how choices about building, implementing and promoting particular technological responses to challenges in particular localities may be tightly aligned with the interests of powerful political and economic actors in ways that can be characterised in terms of colonialism [1]. Van der Velden [2] offers a critique of systems for producing and curating knowledge and how these reflect global power structures and exclude the knowledge of those at the margins. Brown [3] draws attention to the existence of multiple knowledges that tend to attract different weight in the specific power constellation of the development context. A major impediment to collective learning is thus the power hierarchy among the contributing knowledge interests.
Researchers from the global South are under-represented in journals and conferences exploring ICTD [4], and even when researchers from the South are involved, the overall framings of research agendas may already be grounded in corporate and academic Northern knowledge interests. In this setting, authentic concerns and aspirations from the South have become invisible, and knowledge systems that differ from dominant (Northern) discourses may be silenced. It is therefore no surprise that so much ICTD research can be characterised as failing [5] and why Fail Fairs have become so popular at ICTD events.

We contend that the problems in ICTD arise from flawed models of the concept of research for change. In these models, researchers claim to be able to discover what will benefit 'disadvantaged' groups and populations, whilst overlooking their own position of privilege and failing to analyse how their own knowledge interests (and those of other actors) will influence the conduct and outcomes of the research. External researchers flying in and flying out in what Mary Brydon Miller has described as 'bungee research ${ }^{1}$ will exacerbate problems and miss opportunities for emancipatory social change. Currently dominant models deny our shared humanity and mutual respect but also involve an immoral waste of scarce human resources on a global level. If it is to be true to its stated purpose of development, ICTD is clearly in need of some critical alternatives.

Aarhus 2015 offers a unique and timely opportunity to bring together the traditions of critical computing and ICTD to set out alternative frames of reference for future research that could earn the title ICT for Development.

\section{STRUCTURE OF THE WORKSHOP}

Since the purpose of the workshop is to draft a frame of reference for future ICT4D research we invite applicants to submit a short statement describing their experience in this area, set out their ideas about components that should form part of this framework and make a written commitment to the other participants in the workshop that they will have read their submissions before they will turn up on the day. We will share these submissions online, prior to the workshop and read each other's work.

The opening session of the day will provide an opportunity for participants to introduce themselves, set out their concerns and aspirations regarding future ICT4D research and address queries towards other participants regarding the online submissions.

During the second session we will start an appreciative inquiry into the concepts and practices that participants

\footnotetext{
1 Keynote address to the 2013 Connected Communities Showcase and Summit, Edinburgh. http://www.ahrc.ac.uk/News-and-Events/Watch-andListen/Documents/Connected_Communties_Podcast_Trans cript.pdf
} 
have used or experienced that might suggest directions for critical alternatives.

After lunch, we will conclude this first inquiry cycle and review the learning.

The last session will be a planning session about a communication strategy and the next steps.

Because many participants may not be able to attend the Aarhus 2015 conference, we will organise the possibility of remote participation on the basis that participants attend for the whole workshop and engage in all the activities.

\section{ORGANISERS BIOGRAPHIES}

\section{Edwin Blake}

Edwin is Professor of Computer Science and director of the ICT4D research centre at the University of Cape Town. He is recognised as one of the pioneers of applying HCI principles to development challenges through his work on Cybertracker in the 1990s, and he is currently working with action research approaches to support communities in representing, retaining and communicating their own indigenous knowledge using digital IT.

\section{Ineke Büskens}

Ineke is a cultural anthropologist and research methodologist. Having been the head of the centre for research methodology of the South African Human Sciences Research Council for 5 years, she now works as an independent research, gender and facilitation consultant. Since 2004 she has been the leader of the GRACE (Gender Research in Africa and the Middle East into ICT for Empowerment) Network involving 28 teams of researchers in 18 countries operating at the intersection between civil society social action and emancipatory action research.

\section{Andy Dearden}

Andy is Professor of Interactive Systems Design at Sheffield Hallam University. He has been involved in ICTD research for 10 years and was the founding chair of IFIP's special interest group on Interaction Design and International Development. He has written extensively about the methods, approaches and ethics in ICTD research.

\section{REFERENCES}

1. Lilly Irani, Janet Vertesi, Paul Dourish, Kavita Philip, and Rebecca E. Grinter. 2010. Postcolonial Computing: A Lens on Design and Development. In Proceedings of the SIGCHI Conference on Human Factors in Computing Systems (CHI 2010), 1311-20.

2. Maja van der Velden. 2005. Programming for cognitive justice: Towards an ethical framework for democratic code. Interacting with Computers, 17(1), $105-120.2005$.

3. Valerie A Brown, 2010 Multiple Knowledges, Multiple Languages: Are the Limits of My Language the Limits of My World? Knowledge Management for Development Journal 6 (2) 120-31.

4. Shikoh Gitau, Paul Plantinga, and Kathleen Diga. 2010. ICTD research by Africans: Origins, interests, and impact. In Proceedings of the 4th International Conference on Information and Communication Technologies and Development ICTD. 2010.

5. Leslie Dodson, S. Revi Sterling, and John K. Bennett. 2013. Considering Failure: Eight Years of ITID Research. Information Technologies \& International Development. 9(2), 19-34. 